\title{
Benibahita Linnavuori (Hemiptera, Cicadellidae): primeiro registro no Brasil e descrição da fêmea de Benibahita furcillata Linnavuori ${ }^{1}$
}

\author{
Keti M. R. Zanol 2 \\ ${ }^{1}$ Contribuição número 1637 do Departamento de Zoologia, Universidade Federal do Paraná. \\ ${ }^{2}$ Departamento de Zoologia, Universidade Federal do Paraná. Caixa Postal 19020, 81531-980 Curitiba, Paraná, Brasil. \\ Bolsista do CNPq. E-mail: kzanol@ufpr.br
}

\begin{abstract}
Benibahita Linnavuori (Hemiptera, Cicadellidae): first record from Brazil and description of the female of Benibahita furcillata Linnavuori. Benibahita Linnavuori, 1959 is reported for the first time in Brazil; the female of $B$. furcillata is described and the male is redescribed and illustrated.

KEY WORDS. Brazil; Deltocephalinae; Benibahita; new record.
\end{abstract}

RESUMO. Benibahita Linnavuori (Hemíptera, Cicadellidae) é registrado pela primeira vez no Brasil; a fêmea de $B$. furcillata é descrita e o macho é redescrito e ilustrado.

PALAVRAS-CHAVE. Brasil; Deltocephalinae; Benibahita; nova ocorrência.

LinNaVuorı (1959) descreveu Benibahita, monotípico, tendo como espécie-tipo Benibahita furcillata, baseando-se num exemplar macho proveniente da Bolívia. No presente trabaIho, descreve-se a fêmea de $B$. furcillata sendo o primeiro registro do gênero e espécie para o Brasil.

O material estudado pertence à Coleção de Entomologia Pe J.S. Moure, Departamento de Zoologia, Universidade Federal do Paraná (DZUP).

\section{Benibahita furcillata Linnavuori}

Figs 1-8

Fêmea. Coloração geral marrom-clara. Cabeça com quatro manchas pretas intercaladas por manchas amarelas na margem anterior; coroa marrom-avermelhada com uma mancha amarelada, no meio; sutura coronal com uma faixa amarela que se conecta à mancha amarela da margem anterior. Face amarela com manchas marrons. Pronoto amarelado com manchas marrons. Asas anteriores semitransparentes, marrom-claras com manchas marrom-escuras; célula braquial com falsas veias marrons; venação marrom.

Cabeça mais longa medianamente do que junto aos olhos; margem anterior microesculturada; região frontal intumescida e microesculturada; região discal lisa com leves estrias Iongitudinais; sutura coronal não alcançando a metade do comprimento da coroa; ocelos na margem anterior, não visíveis de cima; área ocelo-ocular menor que o diâmetro dos ocelos; su- tura frontoclipeal estendendo-se até os ocelos. Genas sinuosas. Anteclípeo de lados paralelos.

Pronoto mais largo que a cabeça. Asas anteriores com três células anteapicais fechadas; clavo com uma veia extranumerária entre $1 \mathrm{~A}$ e a sutura claval e outra entre as veias anais. Espinulação das tíbias anteriores $1+4$ e dos fêmures posteriores $2+2+1$.

Sétimo esterno com a margem posterior sinuosa e com uma reentrância no meio; superfície com uma mancha longitudinal mediana.

Macho. Semelhante à fêmea. Pigóforo com ápice truncado; sem apêndices. Valva genital triangular. Placas subgenitais triangulares; ápice arredondado; macrocerdas unisseriadas. Estilos com apófises digitiformes, voltadas para fora. Conetivo tão longo quanto e edeago. Edeago simétrico e curvo para cima, com um par de apêndices apicais bífidos.

Comprimento total. Macho 5,10- 5,70 mm. Fêmea 6,20 mm.

Material examinado. Brasil, Mato Grosso: Poconé, Sesc Pantanal, 1.XI.2001. R. Miyazaki leg., 2 machos, 1 fêmea, 11.XII.2002, 3 machos, 16.XI.2001, 4 machos, 1 fêmea.

\section{REFERÊNCIA BIBLIOGRÁFICA}

LINNAVUORI, R. 1959. Revision of the neotropical Deltocephalinae and some related subfamilies (Homoptera). Annales Zoologici Societatis Zoologicae Fennicae Vanamo, Helsinki, 20 (1): 1-370. 

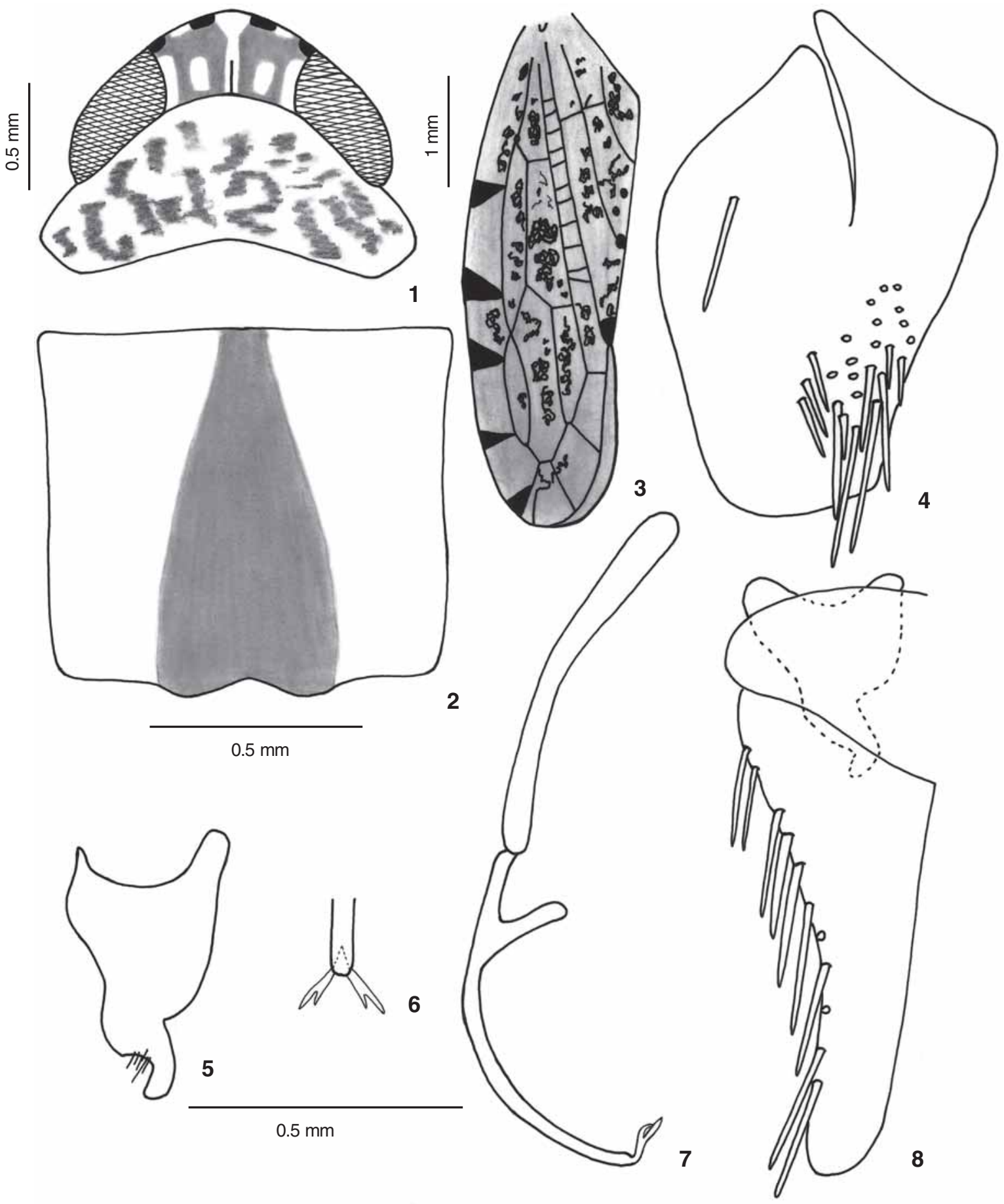

Figs 1-8. Benibahita furcillata: (1) cabeça e pronoto; (2) sétimo esterno; (3) asa anterior; (4) pigóforo; (5) estilo; (6) ápice edeago, visto de cima; (7) conetivo e edeago, lateral; (8) valva genital, placa subgenital e estilo.

Recebido em 21.VI.2006; aceito em 22.XI.2006. 